\section{Steve Wills}

is managing director of Customer Insight Solutions, a company specialising in the management of customer insight as an asset. He spent 15 years with BT involved in setting up a range of new ventures, including BT's telemarketing operations. He then spent time as a business strategy consultant with a major consultancy before seting up and running $a$ successful market research and data analysis agency. He is now a director of three companies involved with various aspects of gathering and managing strategic information.

Keywords: customer insight, strategic asset, insight communication, best practice in customer insight

\section{The management and communication of customer insight}

\author{
Steve Wills \\ Received (in revised form): 13 January 2005
}

\begin{abstract}
Businesses today are demanding ever more insight as they strive to differentiate themselves. But despite our success in generating customer insight from a range of sources, from database analysis through to market research, it is still too often true that this insight rarely reaches all those that it should, and it frequently fails to drive the strategic planning. This paper will examine the reasons why this happens, and puts forward a model for the way that insight should be managed and communicated such that it can deliver its full potential.
\end{abstract}

\section{The start and finish point}

It has always been the case that a business must understand its customers to be truly successful. But only now is this issue genuinely rising to the top of the boardroom agenda. This is because for most of the 20th century the true drivers of success, given reasonable customer understanding, have been efficiency of production and efficiency of sales and distribution. But now all major companies can achieve these, and indeed copy each other very quickly when one finds some new efficiency, so it is ever harder to differentiate. For that reason, customer insight is now being recognised as the best source of sustainable competitive advantage. But paradoxically, achieving true insight is becoming ever harder, for reasons which will be outlined in this paper.

But after reading this paper, if there are just three messages everyone in our industry should go away with, they are these:

- customer insight involves building complete pictures from multiple sources - so no one area can work in isolation to build insight

- customer insight is a strategic asset, as important to a business as its IT

— customer insight must therefore be managed like a strategic asset.

This paper will expand on the reasoning and the basis for these conclusions before then suggesting the kind of approach that companies should consider, and indeed some are already following.

If the message was to be encapsulated in just one thought, it has to be that we need to shift our emphasis away from the generation of insight to the management and onward communication of that insight. 


\section{The project that drove these conclusions}

The project that led to these conclusions started in January 2003. It in fact stemmed from an earlier study in $2000,{ }^{1}$ looking solely at best practice in market research, which had highlighted the fact that communication and establishing the value of research were major weaknesses in most companies. But over the following three years it had become clear that these issues affected all aspects of customer insight (and not just research), and that little progress had been made in addressing them.

Therefore, as with the previous study, a group of 12 major companies

\section{Twelve major sponsors}

\section{All types of insight} (Boots, BAA, British Gas, Coors Brewers, ICI Paints, Masterfoods, Nationwide Building Society, Nokia, Royal Bank of Scotland, Sainsbury's, Standard Life, Vodafone) sponsored a detailed study of this area.

The objectives agreed at the start of the project were:

- to understand how best to manage the knowledge gained through customer insight

- to identify best practice in communicating insight and encouraging insight results to be used by the business

- to establish how a realistic value can be derived for customer insight so that return on investment can be calculated, demonstrated through case studies where possible

- to create a set of practical tools and methodologies that any customer insight function can easily apply to increase the value that they deliver.

Crucially the project scope covered all forms of customer insight — in other words, it covered market research, database analysis, market intelligence, competitor intelligence, insight from customer services staff and from sales staff and so on. And it involved working with key people in departments with very varied names and responsibilities, including CRM.

Although these were the stated objectives, and they broadly remained the same throughout the project, it was accepted that as the project progressed the group might want to revise them. There are two ways in which the final outcome differed. First, the overall conclusions went further than the original objectives suggested. Secondly, the issue of return on investment (ROI) from insight is now seen as crucial, and within the scope of the original project only limited conclusions were drawn. But this has now become 'work in progress', with a workshop on ROI having been run already and further work scheduled.

The project itself involved in-depth exploration of these issues with 27 client-side companies (including the sponsors, and blue-chip organisations from a range of sectors), ranging in length from two hours to over a day. There were further interviews with directors and chief executives of ten major agencies in the fields of advertising, data analysis, PR and communications, and market research in order to validate (from their experience of their own much wider client bases) the views 


\section{Insight has two forms}

expressed in this paper. In addition, a separate study was made of current practice in knowledge management.

\section{What is insight?}

At the very heart of the debate will inevitably be the question of "what is customer insight?'. It is a term that is often bandied around and, unfortunately, now conjures in many people's minds the idea that it is just the new name for data analysis, or market research, or at best some combination of the two. For many it is a cosmetic name change rather than signifying something more fundamental.

At the start of the project, the definition of 'customer insight' was thought to be somewhat of a 'no-brainer' until it was realised just how different the views and approaches of each project sponsor were. It led to the realisation of perhaps the most fundamental learning from the project - that customer insight is not one thing, but two.

Customer insight has two forms. Firstly, and perhaps most often what is requested, there are 'insights' (plural). These are those flashes of inspiration or penetrating discoveries that can lead to specific opportunities. A single piece of analysis, or an ad hoc market research project, can deliver these, and often does. When a marketing department demands more insight, it is typically these flashes, or 'Ah-hah moments', that come to mind.

But much bigger than this, and central to what companies actually need today, is customer insight (singular). The dictionary definition of this type of insight is 'the ability to perceive clearly or deeply'. It is all about having a deep, embedded knowledge about the customers and the market around us that helps structure thinking and sound decision making. Everyone involved in marketing needs this form of customer insight. And arguably, in a customer-focused organisation (as so many currently claim to be) it is something that almost everyone in the organisation should have, at least to some degree.

\section{Customer insight is built from multiple sources}

But this type of customer insight is all about having 'the big picture'. Not just some pieces of a jigsaw, but all the pieces, and joined up to produce a picture that all can see and understand. This is what is needed in the boardroom (the shorthand term 'boardroom' has been used throughout this paper to cover senior management decision making at the top and right across the business), and it comes not just from one source but from a combination of multiple pieces of data from the database(s), market research, financial and planning data, plus the output from the market and competitor intelligence data, plus feedback from sales and customer service staff, including customer complaints. In fact, it is a picture built from any and all sources that may be available - in a coherent format that addresses anomalies and apparent contradictions, and gives appropriate weight to all of them.

At present few boardrooms have this kind of insight. Perhaps the best informed are in the FMCG companies - partly because they have historically built insight-hungry cultures, and partly because the bulk of 
Personnel turnover undermining insight

\section{A house is more than bricks}

their insight does in fact come from one source, namely market research. Because they have fewer sources, it is easier to create a complete and non-contradictory picture. But in most other industries, particularly those with direct contact with their end consumers, there is so much information available from so many sources (with databases often predominant), that creating this 'joined-up' picture is much harder. And few have a structure that formally brings all these sources together.

But it was mentioned earlier that in fact this situation is getting worse, and it is not just because there is so much more information available, causing the classic and widely discussed problem of information overload. The problem of overload has been with us for many years, but something potentially far more worrying has been happening over the last few years - the problem of speed of markets, and the necessary speed of reorganisations and speed of movement of key personnel between roles within companies, and indeed between companies. Five or ten years ago it was still common to find a core of key people in any company who had been in mainstream marketing within that company for many years. So although they may not have had well-developed formal processes for integrating and communicating the many sources of insight, there was in fact a reasonable underlying level of insight built up and maintained by those key people. Often, the person with the longest track record in the marketing department was the market research manager.

Now we have a situation where movement has become so rapid that it is rare to find a long-standing company stalwart in key marketing positions. Most spend only a year or two in any particular post before moving on - carrying with them whatever knowledge they have built up. As such, even basic levels of customer insight and understanding are being constantly eroded, leading to a situation where more and more decisions are being taken from a basis of less and less information.

So building, maintaining and communicating well a structured and integrated bank of customer insight is now becoming an urgent priority. And that need for integration is perhaps demonstrated by use of two analogies.

\section{Two analogies - Construction and IT}

Consider first the house-building industry. The aim is to build wonderful houses that everyone wants to live in. What is the biggest component of any house? Probably the bricks. And part of the construction industry is the brick manufacturers. But can the brick-making companies lead the house-building industry just because they are responsible for the largest part of every house? Of course not! A house is only a house when put together with windows, doors, the roof, the electrics, the plumbing and all the other essential components. But even that is not enough. It needs capable construction, and over everything, it needs the architect to create the vision and produce the overall plan to make the house aesthetically pleasing and functionally workable.

Although many may be offended by this comparison, in our industry data analysis, or market research, or any other individual informationgeneration discipline, is the equivalent of the bricks. And no matter how 


\section{The IT analogy}

much effort the brick makers put into making better bricks, in more shapes, with better properties, they will only ever be part of the overall house. And what people buy is houses, not bricks. In the same way, the board and the marketers in a company need a complete picture of their market and of their customers. Single disciplines alone cannot currently provide this. This is just one reason why management consultants have the high-level impact that we cannot achieve - because their very role is to bring together information from many sources to create complete pictures. So if we want to have maximum influence on the board, and upon company direction, we must build complete pictures of markets and customers from all sources.

Now consider the IT industry. If you go back many years, IBM was famous for the fact that they made computers. Then, we had a computing industry (or some called it 'data processing'). But over time, and as technology advanced, it became clear that what was needed were 'solutions'. And solutions meant the bringing together of mainframes, PCs, data networks, voice networks and a wide variety of software. IBM is no longer in the computer industry - it moved on many years ago to the much broader IT industry, supplying all of these elements, in a way that produced complete solutions. And in a recent Financial Times article, IBM was quoted as undergoing further reorganisation to make it capable of fully integrating technology with overall business processes. 'How technology is applied will be far more valuable than the technology itself.' This is one of the reasons they bought the consultancy arm of PricewaterhouseCoopers.

Indeed, the IT analogy is an important one, because of what it shows about the misunderstanding that can arise over a name. Twenty years ago there was no information technology industry - it was called computing or data processing. When the term IT first emerged it was seen by many as just the computing fraternity trying to give itself a fancy name. But the name change was not just cosmetic. No one would dispute today that information technology covers a huge range, including networks, office systems, software applications, communications etc, and computing is only part of it. In exactly the same way, customer insight is not just a cosmetic name change. It is not analysis or research with knobs on! It is something much broader and much higher value, encompassing a wide range of sources and skills, and is as crucial to an organisation today as its IT.

\section{Customer insight is a strategic asset}

We must start talking about it as such.

The role of a company board is to deploy its assets to the best effect to generate the highest returns. And in years gone by the greatest focus has been on the physical assets - the money, the buildings, the equipment etc. And every board had a finance director responsible for those assets.

More recently, companies have come to realise there are other assets equally, or perhaps more, important. One is the people who work in the company. And most boards therefore have an HR director. 


\section{Struggle to differentiate}

\section{Need for insight director}

And of course there is technology. Getting the IT side right is crucial. So most boards have an IT director.

But over time, most companies' abilities to exploit these assets effectively have developed to the point where they are all, by and large, equally good. That is why in so many industries all the main players are seen as being the same, and they struggle to differentiate themselves. Is Barclays really any different to HSBC or Royal Bank of Scotland? Is there really much difference between Vodafone, Orange, $\mathrm{O} 2$ and T-Mobile?

So now it is being recognised that differentiation will not come by being the cost leader, or by developing the best technology. It will come by being the best at understanding the many and varied needs and characteristics of customers, and developing products and services that truly meet those needs. In other words, real, deep, embedded customer insight.

Now, some may say that marketing has been around for years, and it has always been their role truly to understand the customer. So what is different? The answer is that as companies have grown, they have become further removed from their customers, and in reality they now do not truly know them. A good example of a company which realised this problem is Tesco. Throughout the 1980s and 1990s, it was operating in a highly competitive market and needed to understand its customers to survive. But in 1995 it launched Clubcard, with one of its central aims being to gather in-depth data on its customers. In a recent book ${ }^{2}$ about the development of Clubcard, it quotes the meeting where analysis of the first three months' data was presented to the board. 'Sir Ian MacLaurin spoke from the chair: "What scares me about this," he said, "is that you know more about my customers in three months than I know in 30 years." ' In other words, the Tesco of pre-1995 was like most companies then and now. Whatever they thought, they actually had very limited understanding of their customers. Tesco is now one of the exceptions in that its knowledge of customers has taken giant leaps forward. It is no coincidence that it has leapfrogged Sainsbury's to be the number one supermarket, and that it continues to run Clubcard despite its huge cost in vouchers returned to customers. It knows the value of customer insight as a strategic asset, and it is therefore prepared to invest in it accordingly.

So does this mean that there should be a customer insight director? The author would argue that there should, and believes that it will happen. Indeed, if proof is needed, one of the sponsors of the project that has led to this paper has reorganised and brought together its insight activities, and has recruited a head of customer insight. And the heartening thing is that the only debate they are having is not about which part of marketing that post should report into. The debate is over whether it should report to the marketing director or to the chief executive.

But the real lesson we need to learn from this is that we must start talking the language of the boardroom. We must routinely talk about insight as a strategic asset. We must be arguing for the value of customer insight to be reported in the company report and accounts - just as some are beginning to report the value of brands and of intellectual property, 


\section{Proactive, strategic role}

\section{Different sets of skills}

and are moving towards valuing knowledge in more general terms. To do this there needs to be a fusion of customer insight with sales and financial MIS to provide an overt connection with the bottom line and profit, and to calculate ROI.

\section{A strategic asset must be managed Customer insight management is a new role that must be created}

Let us return to the IT analogy for the moment. IT is a strategic asset. And the role of the IT director is not simply to make sure that the IT is in place and that it works. Indeed, there should be managers whose job it is to do that. The IT director is the one who must ensure that the right technology is being employed, and that is being applied effectively, in order to help the company to deliver the highest returns for its shareholders.

In exactly the same way, customer insight must be managed - to ensure that the right information is being supplied to the right people, at the right time and in the right way, so that it is applied to greatest effect. It is not about making sure that requests for research or for data are met efficiently, because that assumes that those who ask for it know what they need, and that they know how to use it and will actually do so. It is about taking a proactive and strategic role in determining what insight, applied where, will deliver the highest impact, and in ensuring that business processes are fully geared up to apply it.

So what does this say about the skills that are needed? Early in this project, the sponsors debated, and largely accepted, that there are two necessary but quite different skill sets. One is that of the practical, project-oriented analyst or researcher. The other is that of the 'insighter'. The first is about technical expertise, and about detail, while the second is about the ability to see the bigger picture and to interpret results within a wider business context. There have been concerns expressed that the 'insighter' could be seen as the more valuable role. In fact both are essential. They are complementary. But the point is that both roles or skill sets are all about the creation of insight and not its application. While one would hope that any head of insight would indeed possess first-class customer insight skills, it is not a requirement of the role that they can generate insight. What emerged as this project progressed was that this person actually needs a third and quite different set of skills. The skills they need are in understanding business processes, and having the strategic as well as the political skills to ensure that insight is not just generated, but that it is communicated and actioned.

And it is this third set of skills that actually provides the link to management consultancy, because in fact the skills needed by someone involved in insight management are very similar to those of a management consultant. It is for this reason that, if we succeed in moving away from seeing data analysis and market research in isolation to the establishment of a comprehensive customer insight discipline within companies, we will succeed in having the same influence that management consultants often do. It will provide the opportunity for those involved in insight to progress to the very highest levels in the business. The author believes that in years to come time spent in customer 
insight will be an essential step on the road to the top for the real high flyers. No one could make that claim for any of the current separate insight-generation functions. Indeed, the author is not aware of any CEO of any major company who would claim that time spent in market research or data analysis was vital in getting them to where they are today!

\section{What does this mean in practice?}

In the months since the project was completed and the results fed back in working sessions with the sponsors and other major companies, the argument that insight is a strategic asset and needs to managed as such has received universal support up to and including director level. But it then begs the question of what does it actually mean in practice. We have established that it requires a range of skills from the analyst/researcher right through to the equivalent of management consultancy skills for the overall insight director. But where should the focus be? What are the structures required and tools and techniques needed? Further learning from the project has answered these questions and has been published in a full report, ${ }^{3}$ but some of the essential elements are outlined here.

\section{Customer insight can learn from the world of knowledge management}

At the start of the project there was an exploration of the whole discipline of knowledge management (KM) to see if, in fact, many of the questions the project wanted to answer had been answered elsewhere. It was a highly informative stage, but left the researchers surprised that, far from needing to catch up with $\mathrm{KM}$, maybe customer insight is ahead of it! This may seem unrealistic, given how much is currently being invested in KM worldwide, but one can explain.

One of the most valuable things learnt from KM was a very basic idea, and the language to go with it. Essentially, knowledge comes in two forms

\section{Explicit versus tacit knowledge}

- explicit and tacit. Explicit knowledge is that which is recorded, in manuals, documents, databases, intranets, etc. Tacit knowledge is in people's heads, and is based on learning, skills and experience. And much of the drive for KM has come from the recognition that so much of any business's knowledge base is tacit - and therefore, as an asset it is not 'fixed'. If an individual with vital knowledge leaves the organisation, that knowledge is lost.

This idea of tacit and explicit knowledge then leads to four forms of communication:

- explicit to explicit (such as IT data transfers)

- tacit to explicit (formally recording what people know)

- explicit to tacit (getting stored knowledge into people's heads such that it can be applied)

- tacit to tacit (helping people to communicate directly to share knowledge and experience).

The current real difference between customer insight and mainstream 


\section{Making tacit explicit}

\section{Creativity not the key}

$\mathrm{KM}$ is in where the emphasis lies in these forms of communication. The current emphasis of most $\mathrm{KM}$ work in practice is towards making tacit knowledge explicit. It is about helping organisations to capture and secure as an asset the vast amount of knowledge that exists in the heads of its people. (Although it is acknowledged that current leading thinking on $\mathrm{KM}$ goes beyond this, in practice the majority on KM budgets are devoted to this.)

With customer insight, the emphasis is the other way round. Most information is explicit already — in the form of research reports, statistics and presentations - and the issue is that of making it tacit. The goal is to communicate it widely and to get it into the heads of all those who should be using it. So in this sense, the work that we are all doing in learning how to manage and communicate customer insight is potentially leading the world of KM. But the terminology and structure given by thinking in terms of tacit and explicit knowledge is a sound starting point for thinking about the role of insight management.

\section{Communicating insight is $\mathbf{9 0}$ per cent structural}

To address the issues of tools, techniques and structures, the core of the project involved tapping the extensive experience of the sponsors in order to understand what makes customer insight successful, what does and does not work and why. Perhaps the most important conclusion to emerge very quickly was that every organisation is different, and therefore what may work for one may not fit another.

This stage of the project involved visits and interviews to each sponsor company to explore how their insight teams (ie research and database and other teams) were organised, and how they went about their work. It looked at successes and failures in communication, and in onward application of insight. It looked at resources available, in terms of people as well as external budgets where appropriate. It looked at skills and it looked at culture.

At the start of the project, one expectation was that creativity and presentational skills would emerge as a major factor in effective communication. Indeed, it was hoped that the researchers would be able assemble a compendium of ideas, tips, tricks and techniques that would help any insight team to transform the way they worked.

In fact it was found that effectiveness of communication depended upon a wide range of factors, but like so many things the Pareto effect came in. In other words just a few factors actually accounted for the biggest effect. And the four main factors were resources, skills, organisation and planning. And after that, success depended upon a number of approaches, such as measuring the impact of insight and actively helping with implementation of recommendations. What it all said was that the keys to success were 90 per cent structural and process oriented, with only the 'icing on the cake' coming from creativity and presentational techniques. Put simply, if you plan to communicate insight effectively, and have the resources, organisation and primary skills to do it, then it will happen.

The issue of resources inevitably came up, and in most areas of insight 


\section{Three people per £1 $\mathrm{m}$ budget}

\section{The 'Bog Standard'}

it was very hard to establish exactly the right number of people, although in many major companies overall insight teams with headcounts of 40+ were not uncommon. But, in market research at least, a basic rule emerged to relate the number of people to the budget that they handled. In effect it is that for every $£ 1 \mathrm{~m}$ of budget, you need three people to ensure that you achieve maximum ROI. Within the project's set of sponsors there was a range, from one or two which had each researcher responsible for $£ 200,000$ of budget or less up to a few where the researchers were handling a budget of over $£ 1 \mathrm{~m}$ each. The difference was stark. Where the people-to-budget ratio was high, those researchers could become highly involved with the users, ensuring that the right research was being done and that it was used effectively. Where the ratio was low, it was basically a factory, struggling to keep up with simple demand for projects, and where research users were essentially on their own in deciding what they needed and in using it once delivered. In these latter cases it was clear that only a fraction of the value of the research was being achieved. Although this may not seem relevant in the database arena, in fact what it highlighted was that although it was not possible to derive a direct formula for calculating resources outside of market research, it was absolutely the case that problems and issues faced by those database teams who were under-resourced were identical to those in market research.

\section{Simple ideas can have great impact}

But having accepted that core solutions to the problems are structural, it is still the case that presentational and communication skills can have great impact. We know that there are some people who are charismatic presenters and who can bring anything to life. They can be amazingly professional, and they are often seen on the conference circuit telling everyone the apparent secrets of making insight communication happen. But the truth is that, while those kinds of people will almost always succeed in these kinds of areas, they are few and far between. Most of us do not quite have that same talent. But this does not mean that we are not capable of some creative thinking and of having an impact. So one of the pleasures of this project was to find a whole range of ideas that have been used with great success.

An idea that still makes the researchers chuckle when they think of it was introduced by an FMCG company. They wanted people in the marketing department to read more about the research going on and the results it was producing, but were realistic about how little time people had to do it. So they decided to create a mini-newsletter, and to put it in exactly the place they felt people had most time and opportunity to read it. They hung it behind the door in the toilets! And called it - what else? - The Bog Standard! Simple, effective and the company has now even gone on to provide post-it notes and a pen for people to write notes and thoughts in reply to questions raised, and to leave them stuck to the door!

Another great idea was the very simple use of a laminator. One contributor to the study had sat down and pulled together a very neat summary of 'The key things you should know about our customer', gleaned from a range of analysis and research done to that point. They 


\section{Lamination}

\section{Recent exposure}

used PowerPoint to produce something eye-catching and punchy on A4 paper. But they knew that in that state, printed on paper, it would just get put in a pile and forgotten. So they laminated it, and left one on every desk in the departments that they felt appropriate. The result was that it was suddenly transformed from just an interesting sheet of paper into something more official looking, more permanent and clearly meant to be kept and referred to. It tended to be pinned to the partitions between desks, and other staff who saw it came to the research department to see if they could have one. The result was that the message got through. And so now they take care to use the idea sparingly so that it does not lose its impact, but when something short but important needs to be communicated, they laminate!

Many more examples like these emerged, and, while simple, a bit of imagination can go a long way in raising the profile of customer insight.

\section{A model for best practice 'Think like a chief executive'}

By the middle of the project it was clear that the key to insight communication lay in the management of the process rather than the actual insight generation itself. And at first it was suggested that it was effectively about marketing the insight as if it is a product. Many insight teams are part of the marketing department, so they were simply asked what was it that we do for our products and services when marketing to customers that we ought to be doing in marketing insight to the customers within our organisations. Effectively 'think like the marketing director'. And this provided an excellent approach to thinking laterally about the issue. One FMCG sponsor suddenly realised, for example, that they were incredibly scientific in analysing how many times a consumer needs to be exposed to an advert of a certain length to achieve the product awareness and purchase propensity that they wanted. But they never considered insight in the same way! If insight is to be absorbed and acted upon, how often does someone in the marketing department need to see a message before it sinks in? Is the classic two-hour presentation, followed by e-mailing of the slides, the best way? Or are some things better communicated through multiple exposures of short snippets?

But this then led to the next logical step. It was not just about marketing the insight. There were whole issues about what insight should be generated, and when, to fit overall corporate strategic needs. The process of creating insight can be likened to manufacturing. The ROI should be measured, in just the same way as in the overall finances of any organisation. In fact it led to the analogy of treating insight effectively as a business - hence demanding that the process of managing it should be thought of in the same way. In other words, 'think like a chief executive'.

This model was tested with all the sponsors, and although each had a different slant on it because of the nature of the organisation they operated in, in effect all of them agreed that the model was sound. Therefore in producing the report, and the guide to best practice, everything has been organised around the premise of treating insight as a business, and around the head of insight taking on the role and 
responsibilities of a chief executive. In so doing it transforms the insight function from being, typically, a reactive function with a service mentality to being a proactive unit focused on value generation.

The essence of the model is simply this. A chief executive has to think about all aspects of the business. These could be summarised as:

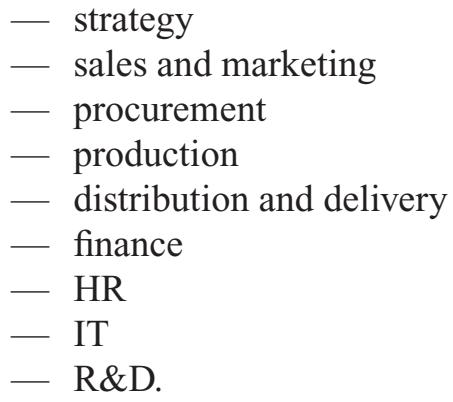

\section{Proactive push}

In the project's model, each of these has a direct analogy for a customer insight function. Its strategy must be aligned with the strategy of the parent company, and the portfolio of insight must be developed to support the company's strategic decisions.

There is then a sales and marketing role, since it was already known that it is not enough simply to expect the potential users of insight in a company to know what is available, and what they should be asking for - it requires a more proactive approach to pushing insight into the organisation rather than relying on simple demand pull. Indeed, some of the sponsor companies had already adopted the equivalent of account managers as primary liaison between their insight functions and their end users.

Procurement requires little explanation in as much as research and intelligence functions already have budgets for buying in the reports and services they need. But by their nature, they tend only to think about procuring their source material from their traditional suppliers (eg research departments buy from research agencies). The chief executive should be asking if there are other sources that are not being tapped such as the agents working in the call centres, or the parent company's own suppliers (which have often also invested in research and analysis).

Production is that process where raw material is turned into something useful - where information becomes insight. But this is an area requiring significant attention in many organisations, particularly in the areas of data integration and reconciliation when involved with multiple and disparate sources.

Distribution and delivery then requires major attention. Is a single twohour PowerPoint presentation really the right way to deliver the results of a major three-month insight project? Distribution must be wider than those at the presentation, and everyone consumes information in different ways. Great improvements in ROI from insight can be gained from addressing the distribution issues correctly.

Just as a chief executive must ensure that a company delivers a profit 


\section{Outsourcing not the answer}

\section{The insight cycle}

and monitor the finances accordingly, so the head of insight should ensure that all their activities are delivering a sound ROI.

And in order to support all these functions, there are then real issues of skills development, technical support and methodological development requiring the equivalent of $H R, I T$ and $R \& D$.

Although the author would not go as far as recommending that customer insight should be outsourced (indeed, the project would recommend the opposite because of the very close communication needs required within the company), as a model for thinking about the issues this approach has proved very powerful.

\section{What is the result?}

An end goal (insight as a strategic asset) and a process for thinking (think like a chief executive) are necessary but not sufficient. What is also needed is a demonstrable output that those outside the insight functions can recognise the value of and buy into.

The project researchers believe that the end result of all the planning should look something like the linked outputs shown in Figure 1 as 'the insight cycle'.

Users of insight will be able to observe a complete cycle that starts with understanding of their own needs to support their jobs, through a clear plan to generate and communicate the range of insight needed, to an efficient and timely process that generates the raw material. The results of that should then be delivered in different formats and at different strategic

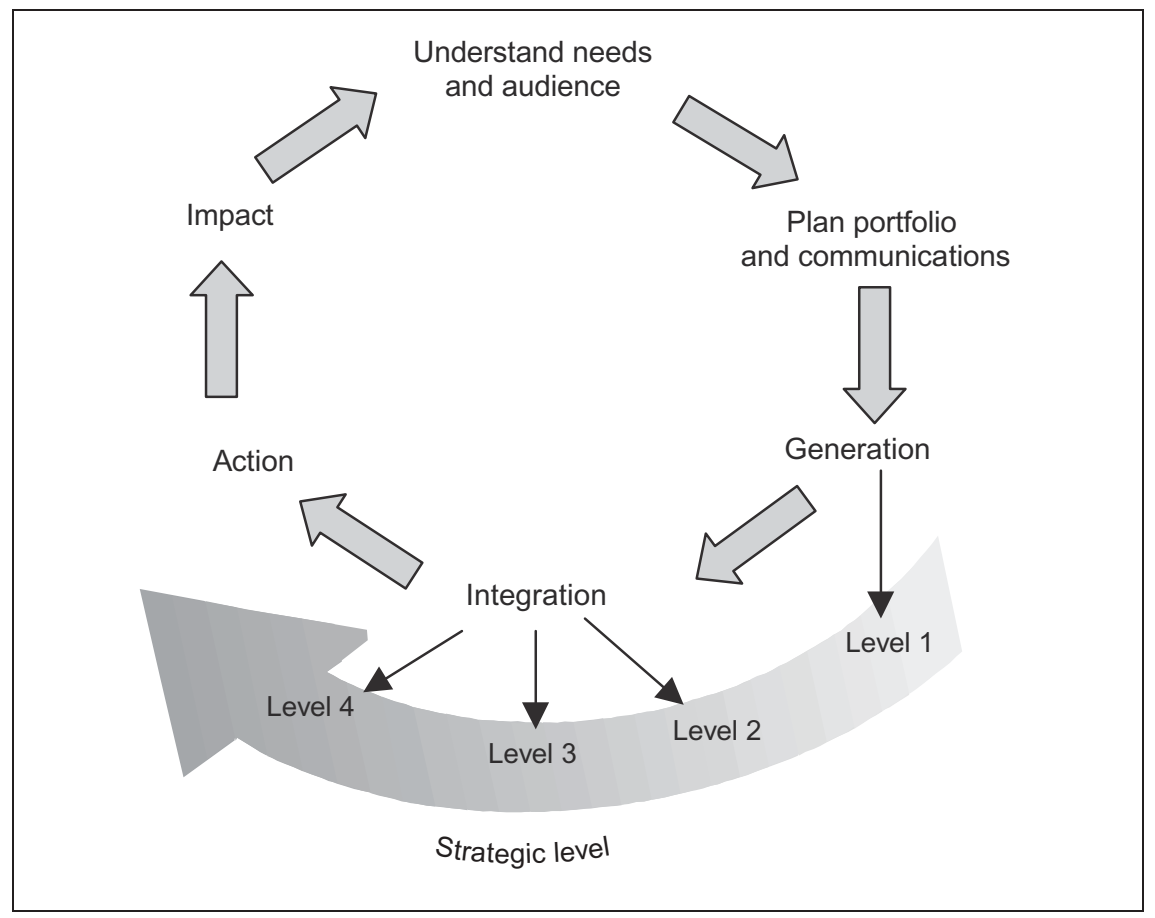

Figure 1: The insight cycle 
Tactical output

\section{Fact packs}

levels to address the full range of issues and needs. These are described as fitting into four levels of insight delivery.

Level 1 is the level that almost all companies currently handle well. This is delivery of results from individual projects and pieces of research and analysis, in isolation. Sometimes this is in fact all that is needed where a user simply requires timely production of core statistics to support tactical planning. But too often single projects are used to address more strategic issues where wider sources of information should be used, and many companies are now recognising that they need to become better at the integration processes that lead to the outputs at Level 2 and above.

Level 2 is that first level of integration. Typically it involves bringing data together to addresses key issues such as retention or cross-sales. It may involve bringing together market research with analysis from the customer database, and then combining these with competitor intelligence to gain a true understanding of what is really driving customer defection, and what the actual behavioural and financial impact will be of, for example, specific improvements in customer service, or of a more reactive sales process to counter competitor initiatives. Benchmarking among a range of companies suggests that this level of integration is now being recognised as a priority in the development of insight function.

Level 3 goes a stage further. Particularly in the current environment of rapid reorganisation and staff movement, there is need to assemble comprehensive 'fact packs'. These might be in effect 'Everything we know about XXX' where XXX might be 'the mortgage market' or 'the over-60s sector' or 'Brand Z'. It will pull together all the research and analysis that has been done in that area and combine it to produce a comprehensive view. It will include internal financial data to show costs and profit margins for specific products and areas of activity. It will included external forecasts and strategic analysis of market trends and opportunities. It will include a history of what the company has already tried - and what worked and what did not. How often do new 'turks' arrive in a marketing department and insist on trying a new approach in order to make their mark, without realising that that same approach was tried some years before and failed? The repeat attempt then fails for precisely the same reasons.

Such Level 3 information is produced in some companies - typically by planning or strategy departments. But it tends to be ad hoc, and produced in response to specific short-term needs. The author believes that a complete portfolio of these fact packs should actually be the goal of any insight function. They will require significant resources to build in the first instance, but once created, maintaining and updating them will be relatively straightforward. The project researchers believe they will be tremendously powerful in supporting strategic decision making, and in allowing all those working in an ever-faster-moving environment to operate immediately with the benefit of a wealth of information and insight gathered over time. In other words, this really is turning insight into a strategic asset. And it provides a stable base to support ever more rapid change.

The final level, Level 4, is the step that shifts the integration above 
Available permanently specific products, brands or market sectors to the overall company level. If Level 3 information exists across all brands or sectors, then developing a company view becomes much easier. This kind of Level 4 view is the classic output from a business strategy assignment conducted by any of the major management consultancies. Unfortunately, too often it is produced again in response to a specific crisis, and produced at speed. But once an insight function has been established properly, and is truly managing insight as a strategic asset, this kind of information will be available permanently, on demand, and provide the tangible evidence of ROI from insight generation and management activities.

But moving on from the levels of insight delivery, the final stages that complete the cycle are those of taking action based upon the insight delivered, and then monitoring and demonstrating the impact of that action. The insight function must play an active role in supporting and driving these elements, especially the monitoring of impact, to ensure that insight is truly delivering the high returns that it should. These are areas that are beyond the scope of this paper, and vast amounts of literature cover these areas and the techniques that companies use - for example techniques like Six Sigma, and the use of balanced scorecards - so the author will not attempt to address them here.

\section{In conclusion}

One can simply repeat the three messages everyone should go away with:

- customer insight involves building complete pictures from multiple sources - so no one area can work in isolation to build insight

- customer insight is a strategic asset, as important to a business as its IT

- customer insight must therefore be managed like a strategic asset.

If we succeed, our industry will have a more secure future and offer more scope for opportunity than it already does.

\section{References}

1. Wills, S. (2000) The Guide to Best Practice in Market Research, CIS, Slimbridge.

2. Humby, C., Hunt, T. and Phillips, T. (2003) Scoring Points, Kogan Page, London.

3. Wills, S. and Webb, S. (2004) Customer Insight Management and Communication, CIS, Slimbridge. 